\title{
Systems with rigidity cores and high-rise buildings outriggers
}

\author{
Viktor Shumeyko ${ }^{1}$, and Anna Karamysheva ${ }^{1, *}$ \\ ${ }^{1}$ Don State Technical University, Gagarina Square, 1, Rostov-on-Don, 344010, Russia
}

\begin{abstract}
The article deals with the problems of applying systems with stiffeners and outriggers for high-rise buildings. The analysis of various designs is carried out, the features of their work are specified, the advantages and disadvantages are identified, the areas of their application. When designing and building high-rise buildings, it is necessary to ensure their resistance to lateral loads arising from wind or seismic influences. The article shows the ways of solving this problem based on various constructive systems. Particular attention is paid to the use of outrigger link systems for providing high-rise buildings rigidity. Various variants of outriggers are investigated in the paper, their advantageous sides and disadvantages are compared, the types of their optimal solutions are determined. A number of technical and economic problems of high-rise buildings with stem systems and outriggers, which have not been sufficiently investigated, are mentioned. Recommendations are given on the use of systems with stiffeners and outriggers to increase the rigidity and lateral stability of high-rise buildings.
\end{abstract}

\section{Introduction}

High-rise construction especially the construction of unique buildings with a height of more than $100 \mathrm{~m}$ and skyscrapers is gaining increasing appeal in Russia and around the world. Against the background of urbanization of cities, the development of megalopolises is impossible at an infinite increase in their area.

Today, large cities tend to climb, rising on a vertical coordinate. High-rise unique buildings are symbols of success, leadership and economic power. The largest companies believe that having a representation in the highest building in the world is a sign of high competitiveness, good advertising, and a symbol of prestige, image and success.

High-rise buildings have their own characteristics and are significantly different from the usual ones.

The characteristic features of high-rise buildings are:

- excess of horizontal loads (winds) over vertical ones;

- high vertical load on the structure, base and foundation;

\footnotetext{
* Corresponding author: kaa-10-07-86@mail.ru
} 
- increased impact on safety from various factors, such as vibration, fire, seismic loads, local destruction, accidents,

- the complexity of ensuring the joint work of load-bearing structures of the building, as well as the uneven loading of walls, columns, and other load-bearing elements.

When designing and constructing high-rise buildings, it is necessary to ensure their resistance to lateral loads arising from wind or seismic influences. Therefore, in practice, various systems for shearing resistance are often used. With the increase in the height of the building, the requirements for greater rigidity of the structure are also growing. For such cases, various systems have been developed, including stiffeners and outriggers of various variants.

Systems with stiffeners provide maximum opportunities to ensure the safety of buildings against progressive destruction.

In Russia, the greatest contribution to the research in the field of high-rise construction was made by the main scientific centers: Concrete and Reinforced Concrete Research Institute of Moscow behalf A.A. Gvozdev, Central Research Institute of Housing, the V.A. Kucherenko Central Scientific Research Institute for Building Structures, MSSU and others.

Studies on altitude systems with stiffening barrels are reflected in the works of Travush V.I., Ilyichev V.A., Telichenko V.I., Almazov V.O., Eremeev P.G., Eremina A.G., Rastorguev B.S., Mrkticheva O.V., Roitman V.M., Perelmuter A.V. and other authors. [1, $2,3]$.

\section{Problems and definitions}

Providing the rigidity of high-rise buildings is one of the most pressing problems in construction. This is the main expense for the design and construction of the building. The lateral stability depends on the effect of wind and seismic loads. The impact of wind on an object depends on its speed, the height of the building, its shape and the type of the lateral surface.

For high-rise buildings, the optimal architecture and construction solutions can be systems with stiffeners. In this case, the trunk forms a system of wall-diaphragms, perceives vertical and horizontal loads and ensures the stability of the building. [4]

Systems with stiffeners may differ in the shape of the trunks, according to their number, location and other characteristics.

Stiffeners are made of reinforced concrete, steel or their combinations. The use of steel trunks is usually limited to buildings of low height due to their low fire resistance and insufficient rigidity. The advantages of such trunks include the possibility of quick installation. More often stiffeners are made of monolithic reinforced concrete. In high-rise buildings, the thickness of the walls of the trunk varies from $40-120 \mathrm{~cm}$ to $20-60 \mathrm{~cm}$.

The shape of the building is of great importance for resistance to lateral loading. They should always prefer symmetrical plans. In asymmetrical buildings, in addition to bending, torques will also arise, which greatly complicates the resistance to wind load.

The horizontal deviation of the building is limited to normative documents. High-rise buildings with a deviation of $1 / 400$ to $1 / 600$ of their height usually refer to stiff.

The stiffener bar or stiffener core is a spatial vertical support system inside the building, in the form of a shell, which perceives vertical and horizontal loads from the wind and possible seismic action. It provides spatial rigidity and stability of the entire building for the period of installation and operation.

In terms of statics, the nucleus acts as a rod of closed or open cross-section, rigidly clamped in the foundation. The kernel remains unchanged in height due to hard horizontal 
disks, diaphragms. The kernel perceives normal forces, shifts in any direction and horizontal loads, including those that cause torque.

In the plan, the core occupies an average of $15-35 \%$ of the building area. Inside the core, there is engineering equipment.

The shape of the core and its placement in the plan can be different. It is possible to place several cores in one building; the main thing is that their position should be symmetrical. For placement the mines of engineering equipment and communications in the cores, walls divide them into sections. These walls can be bearing or - like core filling.

Buildings with stiffeners together with other horizontal and vertical structures form different spatial systems.

Trunk systems. In such systems, the core becomes the only design that perceives horizontal and vertical loads and imparts spatial rigidity to the building. In this system, you can submit several options:

-core, which is adjacent to the cantilevered structure of the floors (cantilever floors);

-core and platform in the form of a console on the lower level, serving as a support for the outer columns above the arranged floors;

- a system that includes a core and floors that are suspended from the top floor and others.

In a system with cantilevered ceilings, the core forms a structure in which the vertical load increases in the direction of the foundation. This system gives maximum freedom to design facades of buildings. However, it is not a commonly used solution due to the flexibility of the console sections. To perceive bending moments in this system, is necessary to use additional reinforcement.

In the console platform system on the lower levels columns lean on this platform. Below the platform, the vertical construction is only the core. In this case, at the level of the lower floors a free space is created in which there are no columns.

The system with suspended ceilings is characterized by the fact that the load is transferred to the cantilever head at the top of the building. The tensile forces in the pendants grow to the top of the building and are transmitted through the cantilever belt to the core of the building, causing the compressive forces in it. In the suspension there are tensile forces and therefore there is no longitudinal bending, and there is no loss of stability against bending.

When designing buildings with suspended ceilings, it is necessary to determine exactly how many floors it is permissible to hang to one belt-head.

A large number of suspended floors can cause unacceptable deflections of the cantilever belt and considerable deformation of the suspension from the action of the load. In the design practice, it is considered that the number of floors that are suspended to one belt should be no more than 15 . If necessary, there should be arranged intermediate belts in height.

Buildings with a stiffened barrel, which is the only vertical bearing structure that operates on vertical and horizontal loads, are rarely used. Combined systems with stiffeners are much more often used.

Combined systems with a hardness kernel. With a combination of the core with other designs, different variants can be obtained:

- a system consisting of a hardness kernel and a framework;

- core and supporting walls or vertical diaphragms of rigidity;

- the core in combination with the contour shell and others.

Systems with a core of rigidity and a skeleton. For most high-rise buildings, the most common architectural and constructive solution is the stem-frame system.

In this combination, the core and vertical elements perceive horizontal loads in many design options. 
The joint work of the core with the frame makes it possible to include vertical structures in the resistance to horizontal loads. This can be solved in various ways:

- lay rigid horizontal diaphragms-grillage on several floors;

- connect the columns with beams on each floor;

- to establish vertical frame or latticed diaphragms between the columns.

In a system with a barrel and stiffening diaphragm, the core is connected to vertical diaphragms by means of overlaps rigid in the horizontal plane. Horizontal loads are distributed between the vertical diaphragms and the core.

In the system with the outer shell, the core has a high load-bearing capacity and rigidity both in bending and in torsion of the shell. This system provides good shear resistance. It is recommended for high-rise buildings.

Systems with kernels are simple for static calculation. However, at a large height of the building (for example, for unique buildings, with a height of more than $100 \mathrm{~m}$ ), such a system no longer refers to rational ones. In this system, it is practically impossible to provide sufficient horizontal stiffness. In this case, systems with nuclei need to be strengthened by other structural systems to provide spatial rigidity.

For tall buildings of a tower type, as a rational variant, there can be a system consisting of a stiffening core and an outer shell of a lattice or frame structure. The joint work of the core and the shell forms a system that has increased strength and rigidity.

The higher the building, the more difficult it is to meet the requirements limiting the lateral shifts, which come into conflict with the architectural and artistic design.

Constructed in Russia and abroad high-rise unique buildings give many examples of schemes to reduce lateral shifts. There are numerous systems of high-rise buildings that resist the horizontal load well.

In these systems, outriggers - spacers connecting the core with external columns, occupy a special place. Outriggers act as dampers, reducing horizontal fluctuations. The outrigger usually consists of a shingling farm that is located along the outer columns, as well as vertical links connecting the central core to the farm. In various designs, there may be two-storied outriggers, as well as outriggers, in which there are no girdling trusses or vertical connections are excluded. The construction of outriggers in each high-rise building is unique and can be different within one object. $[5,6]$

The outrigger system serves to reduce the tipping moment in the core, which would otherwise work as a clean console, and to transfer reduced torque to the columns outside the core, causing tension in them - compressive stresses, which makes it possible to increase the moment arm between the core and these columns.

The use of outrigger systems has several advantages:

- Outrigger systems can be formed in any combination of steel, concrete or composite materials;

- the basic tipping moments and the resulting deformations associated with them can be reduced by the acting inverse moments applied to the core at each intersection of the outrigger. A pair of forces in the outer columns with which the outrigger connects creates this moment. This can potentially increase the efficiency of the structural system;

- Outriggers provide a significant reduction and, possibly, a complete removal of displacements and stresses along columns and foundation systems;

- the outer step of the columns does not cause structural changes and can easily be combined with aesthetic and functional requirements;

- the outer frame can consist of simple beams and columns, without the use of rigid bonds, such as a structure, which leads to an increase in economic indicators;

- for rectangular buildings with elongated facades, outriggers can affect the middle columns when the wind loads in a more critical direction. In single cores and tubular systems, these columns carry significant loads of their own weight or do not work fully. In 
some cases, the outrigger systems can effectively incorporate the gravity forces of almost every column into the lateral load resistance system, leading to significant cost savings. [7]

The most significant drawback of using outrigger systems is their potential impact on free space. This obstacle can be minimized or, in some cases, eliminated by applying various combinations:

- the arrangement of outriggers at technical or intermediate levels;

- location of outriggers in natural sloping lines of the building profile;

- inclusion of multi-level diagonal outriggers, to minimize the impact in one level;

- inclination and displacement of outriggers, in accordance with the functional layout of the premises.

Another potential drawback is the effect that the installation may have on the mounting process. Uniting the outrigger at the intermediate or upper levels, if not approached properly, can have a negative effect on the installation process, so the project documentation provides clear and concise recommendations for mounting.

The kernel and outrigger systems can lead to the following solutions:

- the use of expensive and labor-intensive units and support connections;

- a significant increase in the size of the base solely for resistance to tipping forces;

- the use of time-consuming and expensive socket outlets for connecting the elements of the system.

Outriggers, depending on the method of connecting the outer columns and the core of stiffness, can be divided into 2 types: support and "conditional."

In supporting versions of outrigger systems, beams or trusses are directly connected to columns and a core. In this case, the columns are located along the contour of the building.

In "conditional-virtual" types of outriggers, the transfer of bending moments from the core to the suspension occurs without direct connection of the core to bondage belts. The main thing in this type of solution is the use of overlaps that have high rigidity in the horizontal plane.

Belt bondage belts, connected between the perimeter columns of the building, are practically used in three types: truss, solid and frame. Studies by various authors show that the most optimal are the truss belts. [8]

Belt trusses as side supports of outriggers make it possible to exclude a number of problems when designing high-rise buildings in comparison with conventional outrigger systems:

- absence of connecting rods between the core and the outer columns of the building (from the core of rigidity to belts);

- system core + reinforced concrete floors + truss belt reliably provide lateral rigidity of the high-rise building;

- not only remote support columns, but all contour columns resist tipping points;

- tipping moments from horizontal loads decrease from the action of the inverse moments applied to the nucleus from outrigger bonds.

\section{Conclusions and recommendations}

The use of rigidity kernels in the construction of high-rise buildings gives certain economic advantages in reducing the consumption of steel in the reinforcement of structures, reducing the number of types of sizes of prefabricated structures, and reducing capital investments in the organization of construction.

However, it should be mentioned that a number of technical and economic issues and questions of erecting hardness kernels have not been adequately studied. These include:

- Determination of the optimal solution of the hardness kernels according to the plan and height configuration, wall sections, concrete grade and reinforcement; 
- determination of the economic effect in the construction of high-rise buildings according to the stiffness core scheme + full-assembled structures;

- choice of rational type of formwork for monolithic cores and technology of erection depending on the plan and height of the building;

- determination of the area of optimal use of monolithic cores for high-rise buildings.

The outrigger arrangement reduces the dependence of the high-rise building on the stiffness core and makes it possible to increase the space from the core to the outer columns. This gives a variety of its functional application.

The use of hardness cores in combination with outrigger systems allows increasing the rigidity of a high-rise building, reducing the thickness of its core, and the reinforcement area.

\section{References}

1. V.O. Almazov, Construction and Reconstruction, 6 (56), 3-10 (2014)

2. V.O. Almazov, A.I. Plotnikov, V.S. Rastorguev, Bulletin of the Moscow State University of Economics and Finance, 2-1, 16-20 (2011)

3. V.I. Telichenko, Proceedings of the General Assembly of RAACS, 1, 236-241 (2006).

4. V.I. Travush, High-rise buildings, 2, 32-35, (2014)

5. V.I. Shumeiko, Scientific Review, 13, 97-100, (2016)

6. V.I. Shumeyko, MATEC Web Conf International Science Conference SPbWOSCE2016 "SMART City", 106, (2017)

7. V.I. Shumeyko, A.A. Karamysheva, Engineering studies, 9, 696-702, (2017)

8. N.A. Chernukha, P.I. Gorelik, Lepeshkina D.O., N.A. Chernova, Construction of unique buildings and structures, 9 (36), 18-32 (2015) 